\title{
Enhancement of NAD+-dependent SIRT1 deacetylase activity by methylselenocysteine resets the circadian clock in carcinogen- treated mammary epithelial cells
}

\author{
Mingzhu Fang ${ }^{1,2,3,4,5}$, Wei-Ren Guo ${ }^{1}$, Youngil Park ${ }^{6}$, Hwan-Goo Kang ${ }^{6}$, Helmut Zarb| ${ }^{1,2,3,4,5}$ \\ ${ }^{1}$ Robert Wood Johnson Medical School, Rutgers, The State University of New Jersey, Piscataway, NJ, USA \\ ${ }^{2}$ School of Public Health, Rutgers, The State University of New Jersey, Piscataway, NJ, USA \\ ${ }^{3}$ Environmental and Occupational Health Sciences Institute, Rutgers, The State University of New Jersey, Piscataway, NJ, USA \\ ${ }^{4}$ NIEHS Center for Environmental Exposures and Disease, Rutgers, The State University of New Jersey, Piscataway, NJ, USA \\ ${ }^{5}$ Cancer Institute of New Jersey, Rutgers, The State University of New Jersey, Piscataway, NJ, USA \\ ${ }^{6}$ Veterinary Drugs \& Biologics Division, Animal and Plant Quarantine Agency, Anyang 430-757, Republic of Korea \\ Correspondence to: \\ Mingzhu Fang, e-mail: fang@eohsi.rutgers.edu \\ Keywords: circadian clock, N-methyl-N-nitrosourea, methylselenocysteine, period 2, SIRTI \\ Received: August 31, 2015 \\ Accepted: October 13, 2015 \\ Published: October 26, 2015
}

\section{ABSTRACT}

We previously reported that dietary methylselenocysteine (MSC) inhibits $\mathrm{N}$-methyl-N-nitrosourea (NMU)-induced mammary tumorigenesis by resetting circadian gene expression disrupted by the carcinogen at the early stage of tumorigenesis. To investigate the underlying mechanism, we developed a circadian reporter system comprised of human mammary epithelial cells with a luciferase reporter driven by the promoter of human PERIOD 2 (PER2), a core circadian gene. In this in vitro model, NMU disrupted cellular circadian rhythm in a pattern similar to that observed with SIRT1-specific inhibitors; in contrast, MSC restored the circadian rhythms disrupted by NMU and protected against SIRT1 inhibitors. Moreover, NMU inhibited intracellular $\mathrm{NAD}^{+} / \mathrm{NADH}$ ratio and reduced $\mathrm{NAD}^{+}$-dependent SIRT1 activity in a dose-dependent manner, while MSC restored NAD ${ }^{+}$/ NADH and SIRT1 activity in the NMU-treated cells, indicating that the NAD+-SIRT1 pathway was targeted by NMU and MSC. In rat mammary tissue, a carcinogenic dose of NMU also disrupted $\mathrm{NAD}^{+}$/ NADH oscillations and decreased SIRT1 activity; dietary MSC restored NAD ${ }^{+}$/NADH oscillations and increased SIRT1 activity in the mammary glands of NMU-treated rats. MSC-induced SIRT1 activity was correlated with decreased acetylation of BMAL1 and increased acetylation of histone 3 lysine 9 at the Per2 promoter E-Box in mammary tissue. Changes in SIRT1 activity were temporally correlated with loss or restoration of rhythmic Per2 mRNA expression in NMU-treated or MSC-rescued rat mammary glands, respectively. Together with our previous findings, these results suggest that enhancement of NAD ${ }^{+}$-dependent SIRT1 activity contributes to the chemopreventive efficacy of MSC by restoring epigenetic regulation of circadian gene expression at early stages of mammary tumorigenesis.

\section{INTRODUCTION}

The circadian clock regulates a wide range of cellular and physiological processes in a precise and sustained rhythm with a periodicity of $\sim 24 \mathrm{hrs}$. The clock comprises molecular oscillators functioning in both the central pacemaker (suprachiasmatic nucleus, $\mathrm{SCN}$ ) and the cells composing most peripheral tissues. In mammalian cells, the periodicity of circadian clock is regulated by interconnected transcriptional/translational feedback loops. Heterodimers of circadian transcription factors, BMAL1 (Brain-Muscle Arnt-Like protein 1) and either CLOCK or NPAS2, regulate transcription by binding to E-box elements in the promoters of core circadian 
genes (CGs) [e.g., Period (Per) gene], and numerous circadian-controlled genes (CCGs) (e.g., hormone receptors, growth associated genes and DNA damage response and repair genes) [1]. As circadian proteins accumulate in the cell, they are post-translationally modified and transported to the nucleus to repress or activate Clock:Bmall transcriptional activity. In this way, core circadian genes limit their own transcription and set up the rhythmic expression of CGs and CCGs [2]. These intrinsic molecular oscillators can be reset by external signals including light, genotoxic stress, nutrients, hormones, and environmental signals [1-4]. Thus, circadian clocks integrate a wide variety of environmental and cellular inputs to maintain normal cellular and physiological homeostasis under changing conditions.

One of the important functions of circadian clock is to regulate the organism's response to genotoxic stress (e.g., carcinogen exposure). The circadian clock regulates the transcription, translation, and post-translational modification of $\sim 10 \%$ genes involved in DNA damage response and repair and cell-cycle progression [5]. Circadian rhythm also can be reset or disrupted by genotoxic agents, increasing the susceptibility of cells to DNA damage and carcinogenesis [6-8]. As a result, disruption of circadian rhythm by lifestyle, occupational, and genetic factors has been associated with an increased risk of various types of cancers, including breast cancer $[9,10]$.

The promoting effect of circadian disruption on carcinogenesis is consistent with the finding that Per2 has tumor suppressing activity [2]. Knocking out or mutating Per2 increases cancer cell growth, and accelerates spontaneous and carcinogen-induced tumor development in rodents. By contrast, normal or ectopic expression of clock genes induces cell cycle arrest and sensitizes cancer cells to DNA damage-induced apoptosis after exposure to genotoxic stress. Decreased expression of circadian genes is observed in various human cancers, including breast cancer, and genetic variants, mutations, and epigenetic modifications of CGs are associated with invasive and aggressive breast cancer [2, 11, 12]. In addition, Per2 links the circadian cycle to estrogen receptor signaling $[13,14]$. These findings indicate that maintenance of normal rhythmic expression of CGs (e.g., Per2) plays an important role in suppression of mammary tumorigenesis.

Restoration of normal circadian rhythm has been linked to chemopreventive activity of dietary organic selenium $(\mathrm{Se})$ in our recent studies $[13,15]$. Selenium is a trace element essential to numerous biological processes, including antioxidant defense systems, thyroid hormone metabolism, and immune function [16]. Both epidemiology and animal studies have revealed that selenium compounds have chemopreventive activity against various cancers, including breast cancer. In particular, L-methyl-selenocysteine (MSC) and its metabolites showed the greatest inhibitory effect on mammary and prostate tumorigenesis, especially during early stages, in rodent models [16, 17]. Furthermore, MSC also improves therapeutic efficacy and ameliorates systemic toxicity of anticancer drugs in various animal models [18, 19]. Multiple mechanisms have been proposed to explain selenium-mediated chemoprevention; however, many unsuccessful clinical trials indicated that more mechanistic studies are needed for development of effective intervention strategies [20]. Recent in vitro studies showed that selenium compounds protect against peroxynitrite-induced DNA damage through glutathionemediated redox cycling [21]. MSC induces cell senescence through activation of the ATM-mediated DNA repair upon exposure to genotoxic and oxidative stresses [22]. The latter effects are supported by clinical intervention studies showing that selenium supplementation reduced oxidative DNA damage and cancer incidence in carriers of BRCA1 mutations [23]. Moreover, selenium modulates multiple transcription factors activities involved in cellular responses to stress, including NFKB [24], p53 [25], and BMAL1 [18]. Selenium compounds also up-regulate tumor suppressor gene expression by inhibiting the activity of histone deacetylases (HDACs) [26] and DNA methyltransferases [27].

Our previous studies demonstrated that in vivo exposure to carcinogen disrupts the circadian clock of target tissues. Our studies were the first to link chemopreventive efficacy of organic selenium to restoration of circadian clock in carcinogen-exposed rats $[13,15]$. Exposure to a single carcinogenic dose of $N$-nitroso- $N$-methylurea (NMU) resulted in an apparent disruption in the rhythmic expression of CGs and CCGs in the mammary glands of female Fisher rats at day 30 postexposure. Dietary MSC, given at chemopreventive dose for 30 days beginning after carcinogen exposure, reduced the incidence of mammary adenocarcinoma by $\sim 60 \%$ $[15,28]$. MSC also reset and enhanced the rhythmic expression of CGs, especially Per2, and CCGs, including several growth-regulatory genes and DNA damage responsive and repair genes [13, 15]. In the present study, we investigated the mechanisms by which MSC is able to reset and to enhance CG expression disrupted by the carcinogen. The protracted time course and reversibility of NMU-initiated effects by MSC suggested that both NMU and MSC might alter epigenetic regulation of circadian gene expression [29]. Consistent with this possibility, previous studies implicated phosphorylation of histone $3(\mathrm{H} 3)$ at serine 10 as a regulator of circadian gene expression [30]. Further studies documented rhythmic acetylation of $\mathrm{H} 3$ on circadian gene promoters, with a peak acetylation corresponding with peak transcription [31]. The discovery that the circadian transcription factor, CLOCK, has intrinsic histone acetyltransferase activity further implicated chromatin remodeling in regulation of CGs and CCGs [32]. The NAD ${ }^{+}$-dependent deacetylase, Sirtuin 1 (SIRT1) counterbalances CLOCK-directed acetylation of its hetero-dimerization partner, BMAL1 at 
lysine 537, and histone 3 at lysine 9 (H3K9) [33]. Genetic ablation or pharmacological inhibition of SIRT1 activity disturbs circadian acetylation of H3 and BMAL1 [33]. Given that the SIRT1 activity is regulated by intracellular $\mathrm{NAD}^{+} / \mathrm{NADH}$, we investigated the effects of NMU and MSC on the NAD ${ }^{+}$-SIRT1 pathway and their impact on mammary circadian clock using both in vitro and in vivo models.

\section{RESULTS}

\section{MSC restored cellular circadian rhythms disrupted by NMU and SIRT1 inhibitors in mammary epithelial cells in vitro}

We previously reported that dietary MSC inhibits NMU-induced mammary tumorigenesis by resetting circadian gene expression disrupted by the carcinogen at early stages of tumorigenesis. To investigate the underlying mechanisms, we developed a circadian reporter system comprising human mammary epithelial cells with a destabilized firefly luciferase reporter driven by the promoter of human PER2. The PER2 promoter was selected as a surrogate for circadian gene expression in our in vitro system, because it has been demonstrated in our previous in vivo studies to be the major clock gene linking the circadian rhythm and chemoprevention and it is known to be directly regulated by the circadian transcription factor, BMAL1:CLOCK. Using this reporter system, we were able to monitor the cellular circadian rhythm of gene expression in vitro for couple of days after synchronization.

Untreated, transiently transfected cells (control group) showed two complete cycles of luminescence signaling after synchronization (Fig. 1A). Treatment with $0.25 \mathrm{mM}$ NMU did not disrupt the cellular circadian rhythm. Exposure to $0.5 \mathrm{mM}$ NMU initially delayed and later abolished circadian rhythm, as indicated by disappearance of the second peak of luminescence at $\sim 50$ hours post-treatment. Inhibition of SIRT1 activity with $20 \mathrm{nM}$ Ex257 (SIRT1 specific inhibitor) or $1 \mu \mathrm{M}$ cambinol (SIRT1 and SIRT2 dual inhibitor) similarly disrupted circadian rhythm by dampening the subsequent circadian cycle (Fig. 1A囚). Importantly, addition of MSC $(12.5 \mu \mathrm{M})$ into culture medium restored circadian rhythm in NMUtreated cells towards the normal in both first and second cycles. MSC not only restored the rhythm disrupted by NMU but also prevented the disruptive effects of SIRT1 inhibitors, Ex257 and cambinol (Fig. 1A囚).

In stably transfected cell lines, both NMU and SIRT1 inhibitors disrupted circadian rhythm, albeit at higher concentrations than that observed in transient transfectants (Fig. 1B囚). MSC $(12.5 \mu \mathrm{M})$ restored circadian rhythms in the cells pretreated with $1 \mathrm{mM}$ NMU (Fig. 1B囚). More importantly, MSC also restored circadian rhythms in the cells treated with SIRT1 inhibitors, including EX257
(40 nM) (Fig. 1B囚) and cambinol (2 $\mu \mathrm{M})$ (Fig. 1B囚), respectively.

\section{MSC counteracts NMU to restore SIRT1 activity and $\mathrm{NAD}^{+} / \mathrm{NADH}$ ratio in mammary epithelial cells in vitro}

In order to test our hypothesis that NMU and MSC modulate the mammary circadian clock by altering $\mathrm{NAD}^{+}$-SIRT1 pathway in mammary epithelial cells, we further determined the SIRT1 activity in the human mammary epithelial cells after treatment with MSC for 72 hours following exposure to NMU for 1 hour. Our results indicated that NMU induced a dose-dependent decrease in SIRT1 activity, while addition of MSC at the concentration $(12.5 \mu \mathrm{M})$ that can restore the cellular circadian rhythm disrupted by NMU or SIRT1 inhibitors, significantly increased SIRT1 activity in the cells treated with $0.5 \mathrm{mM}$ NMU, without a significant effect on the untreated control cells (Fig. 2A). These results suggested that the inhibitory effect of NMU on SIRT1 activity may be at least partially responsible for the disappearance of the second peak of cellular circadian rhythm in the reporter cells, while induction of SIRT1 activity by MSC rescued the second cycle of rhythm disrupted by NMU (Fig. 1). These findings demonstrate that NMU and MSC alter cellular circadian rhythm by modulating SIRT1 activity. However, increasing doses of either NMU $(0-1 \mathrm{mM})$ or MSC $(0-25 \mu \mathrm{M})$ showed no significant effect on purified recombinant SIRT1 enzyme activity ex vivo (data not shown), indicating that neither compound directly modulates SIRT1 protein deaceylase activity.

We further observed that the intracellular $\mathrm{NAD}^{+} / \mathrm{NADH}$ ratio was decreased as a function of increasing dose $(0-0.5 \mathrm{mM})$ of NMU. MSC significantly increased $\mathrm{NAD}^{+} / \mathrm{NADH}$ in a dose-dependent manner in the cells pretreated with NMU, but not in untreated control cells (Fig. 2B). These results indicate that NMU and MSC modulate SIRT1 activity by changing $\mathrm{NAD}^{+} / \mathrm{NADH}$ in mammary epithelial cells.

\section{MSC restored the NMU-disrupted circadian expression of Per 2 mRNA in rat mammary glands in vivo}

To test whether the effects of NMU and MSC on cellular circadian rhythm in vitro can also be observed in vivo, we examined the rhythmic expression of Per2 in mammary glands of pubertal female rats at day 2 or 30 following exposed to NMU and maintained on MSCenriched diet or control diet. An apparent circadian rhythm of Per 2 mRNA expression was observed in mammary glands of control rats. Exposure to a single carcinogenic dose of NMU induced a gradual and persistent, time-dependent decrease in the rhythmic expression of Per 2 mRNA in mammary glands of rats. 
A

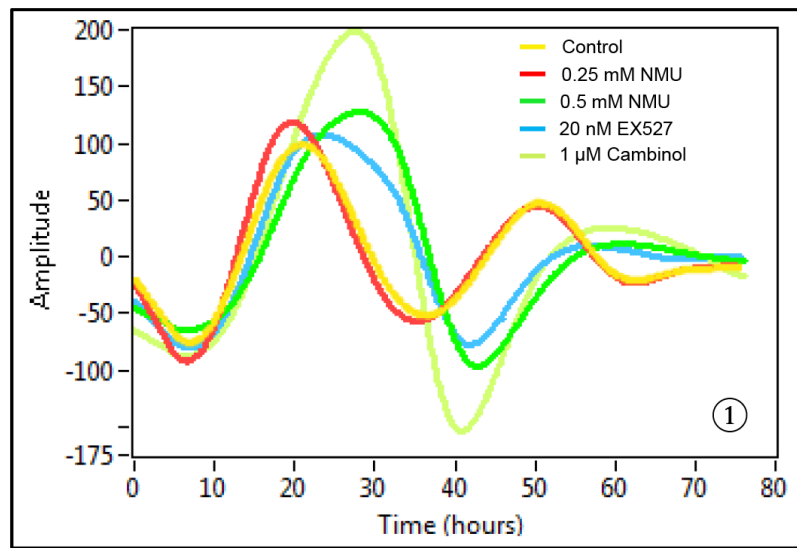

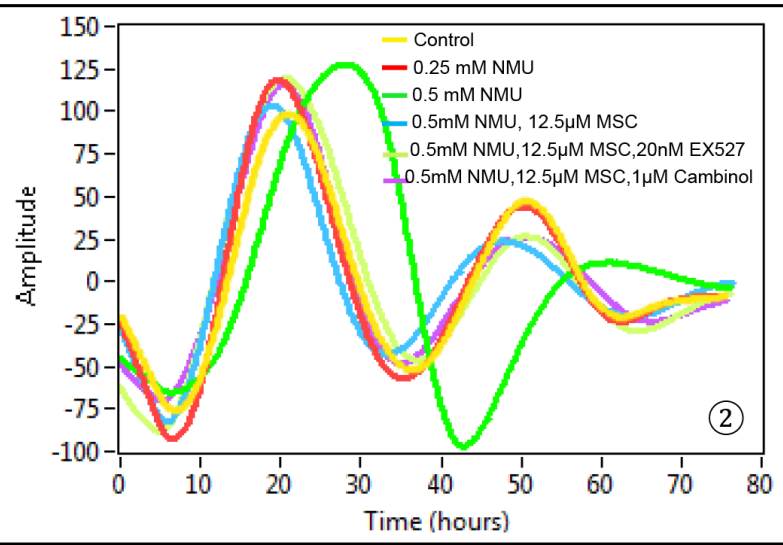

B
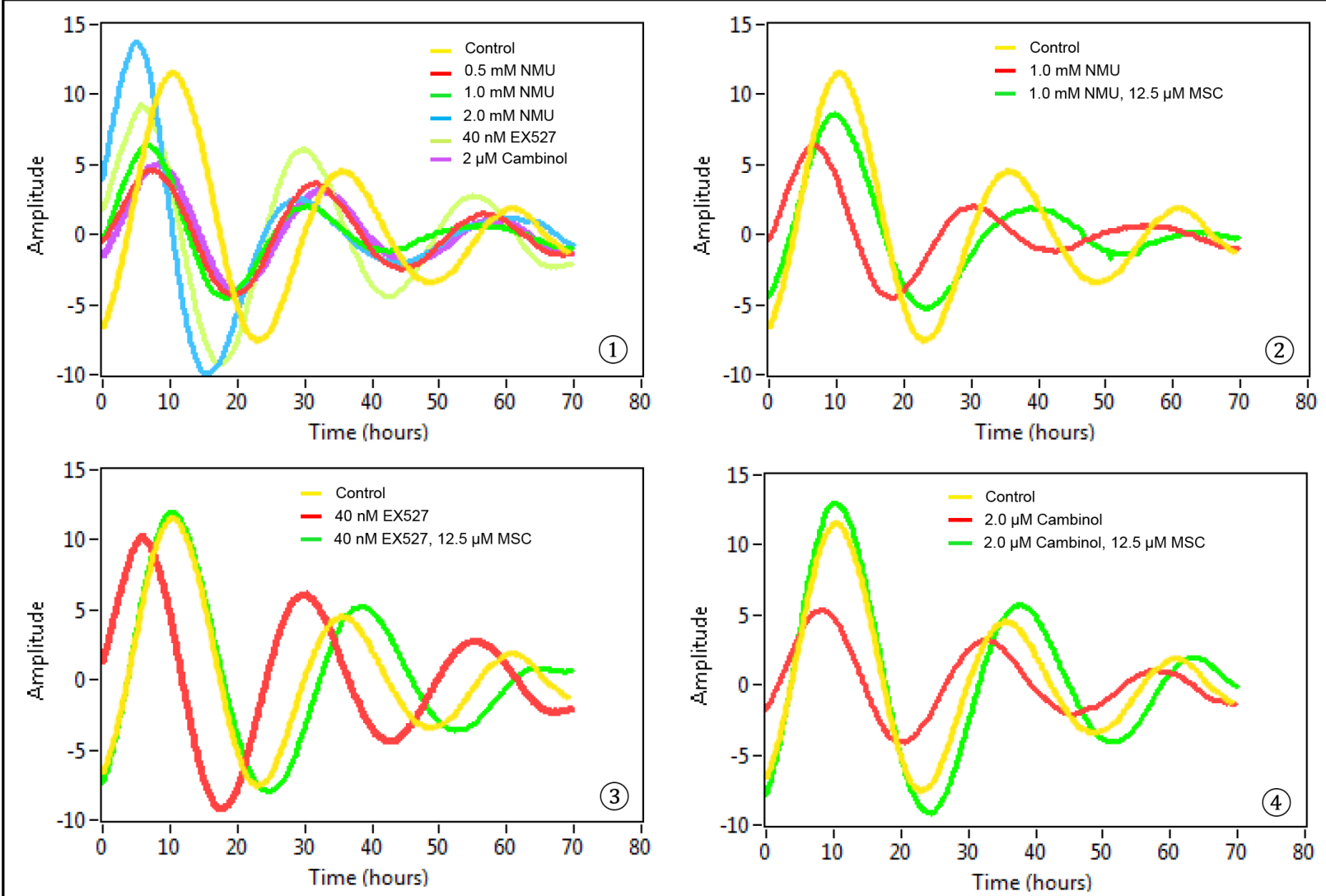

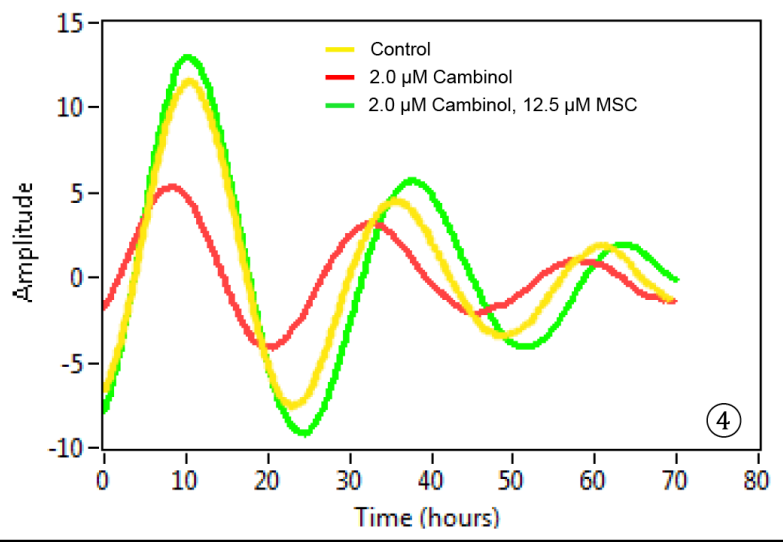

Figure 1: MSC restored cellular circadian rhythms disrupted by NMU and SIRT1 inhibitors in mammary epithelial cells in vitro. Bioluminescence assays were performed on MCF10A/PER2-dLuc reporter cells after synchronization with $50 \%$ horse serum. X-axis, time (hours) (post-NMU treatment time); Y-axis, amplitude. A. Results from transiently transfected cells. $\nabla$ Cells were

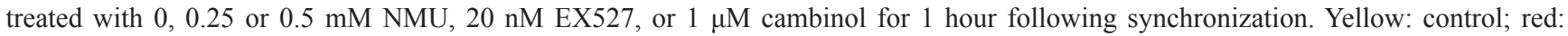
$0.25 \mathrm{mM}$ NMU; green: $0.5 \mathrm{mM}$ NMU; blue: $20 \mathrm{nM}$ EX527; yellow green: $1 \mu \mathrm{M}$ cambinol. $\otimes$ Cells were treated with $12.5 \mu \mathrm{M}$ MSC alone, or in combination with $20 \mathrm{nM}$ EX527 or $1 \mu \mathrm{M}$ cambinol in recording medium following exposure to $0.5 \mathrm{mM}$ NMU. Yellow: Control; red: $0.25 \mathrm{mM}$ NMU; green: $0.5 \mathrm{mM}$ NMU; blue: $0.5 \mathrm{mM} \mathrm{NMU}+12.5 \mu \mathrm{M}$ MSC; yellow green: $0.5 \mathrm{mM}$ NMU + $12.5 \mu \mathrm{M} \mathrm{MSC}+20 \mathrm{nM}$ EX527; purple: $0.5 \mathrm{mM} \mathrm{NMU}+12.5 \mu \mathrm{M}$ MSC $+1 \mu \mathrm{M}$ cambinol. B. Results from stably transfected cells. $\otimes$ Cells were treated with $0,0.5,1.0$ or $2.0 \mathrm{mM}$ NMU, $40 \mathrm{nM}$ EX527, or $2 \mu \mathrm{M}$ cambinol for 1 hour after synchronization. Yellow: Control; red: $0.5 \mathrm{mM}$ NMU; green: $1.0 \mathrm{mM}$ NMU; blue: $2.0 \mathrm{mM}$ NMU; yellow green: $40 \mathrm{nM}$ EX527; purple: $2 \mu \mathrm{M}$ cambinol. $\otimes$ Cells were treated with $12.5 \mu \mathrm{M}$ MSC in recording medium following exposure to $1.0 \mathrm{mM}$ NMU. Yellow: Control; red: $1.0 \mathrm{mM} \mathrm{NMU}$; green: $1.0 \mathrm{mM} \mathrm{NMU}+12.5 \mu \mathrm{M}$ MSC. $\nabla$ Cells were treated with $12.5 \mu \mathrm{M}$ MSC following exposure to $40 \mathrm{nM}$ EX257. Yellow: Control; red: $40 \mathrm{nM}$ EX257; green: $40 \mathrm{nM}$ EX257 + $12.5 \mu \mathrm{M}$ MSC. $\otimes$ Cells were treated with $12.5 \mu \mathrm{M}$ MSC following exposure to $2 \mu \mathrm{M}$ cambinol. Yellow: Control; red: $2 \mu \mathrm{M}$ cambinol; green: $2 \mu \mathrm{M}$ cambinol $+25 \mu \mathrm{M}$ MSC. 


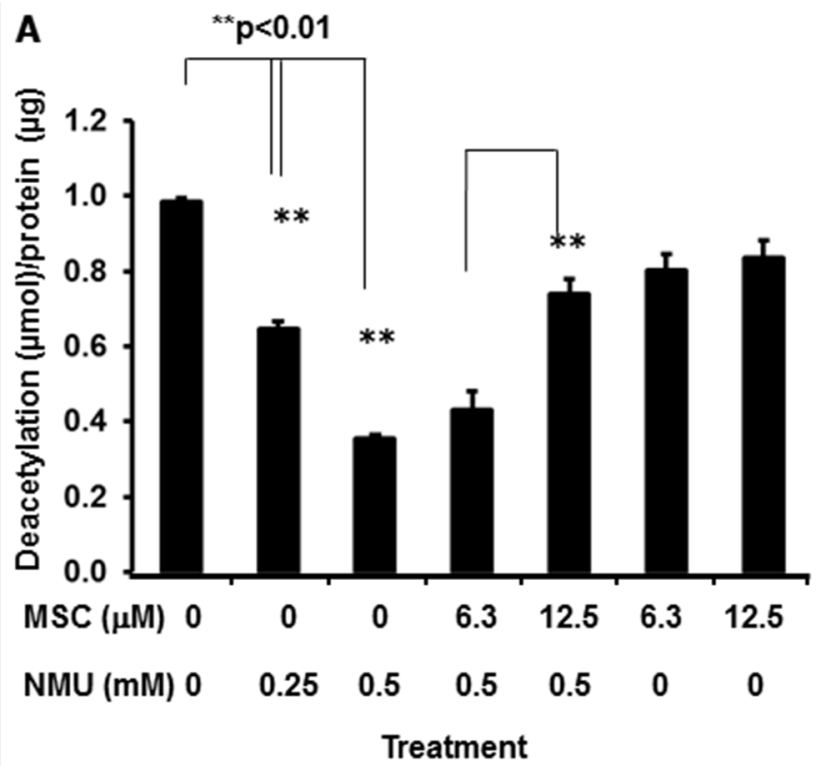

B $\quad{ }^{*} p<0.05 ;{ }^{* *} p<0.01$

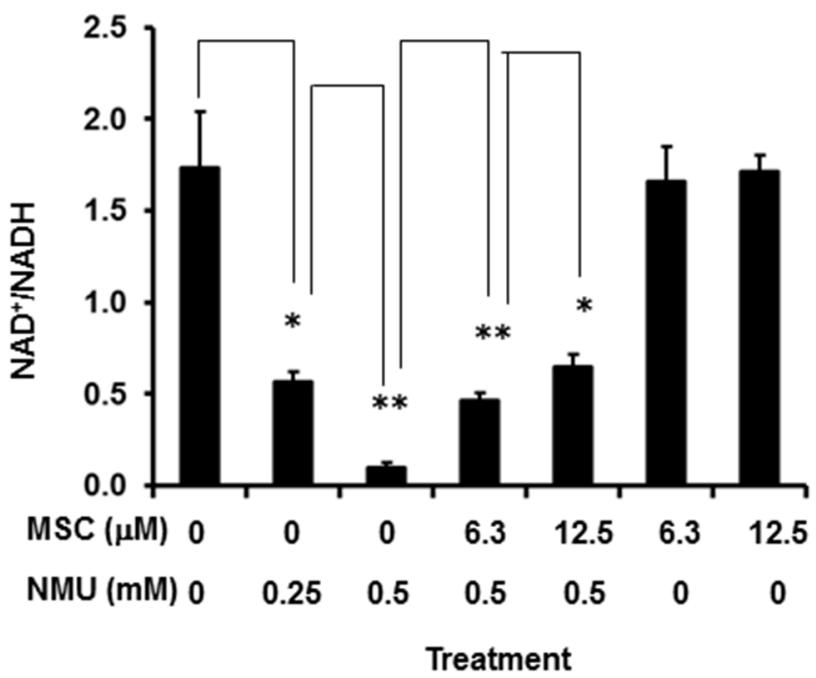

Figure 2: MSC counteracts NMU to restore SIRT1 activity and NAD ${ }^{+} / \mathrm{NADH}$ in mammary epithelial cells in vitro. MCF10A cells were treated with NMU for 1 hour, followed by treatment with MSC for 72 hours at indicated concentrations. A. Total protein samples extracted from cells were used in determination of SIRT1 activity. X-axis: treatment group; Y-axis: SIRT1 activity, shown as deacetylated product $(\mu \mathrm{mol})$ /protein $(\mu \mathrm{g})$, mean $\pm \mathrm{SE}(n=3)$. B. Cell extracts were prepared and used in $\mathrm{NAD}^{+} / \mathrm{NADH}$ quantification. X-axis: treatment group; Y-axis: $\mathrm{NAD}^{+} / \mathrm{NADH}$, mean $\pm \mathrm{SE}(n=3) . *$ And $* *$ indicate statistical significance at $p \leq 0.05$ and $p \leq 0.01$, respectively.

The slight disruptive effect of NMU on the rhythmic expression of Per2 mRNA was first detectable two days after exposure, and it progressed to complete disruption by day 30 (Fig. 3A). A dietary supplement of MSC given for 30-days after NMU not only prevented and/or reversed the disruptive effects of NMU on circadian rhythm, but also significantly enhanced the rhythmic expression of Per2 (Fig. 3B). These results recapitulated our in vitro results and reproduced our previous observation in vivo [13].

\section{MSC reset the circadian rhythm of $\mathrm{NAD}^{+} / \mathrm{NADH}$ and increased SIRT1 activity in mammary glands of NMU-treated rats in vivo}

Next, we examined if the effects of NMU and MSC on $\mathrm{NAD}^{+} / \mathrm{NADH}$ and SIRT1 activity that we observed in vitro also happened in rat mammary tissue in vivo during mammary tumorigenesis. $\mathrm{NAD}^{+} / \mathrm{NADH}$ in mammary glands of control rats showed a normal circadian pattern over a 24-hour period, with a peak at ZT4-8. At day 30 after exposure to NMU, the circadian oscillation in the $\mathrm{NAD}^{+} / \mathrm{NADH}$ was ablated as compared to the control. However, dietary MSC restored both the rhythm and the levels of $\mathrm{NAD}^{+} / \mathrm{NADH}$ to those seen in control rats, and reset the circadian phase, with the peak at ZT8 (Fig. 4A). Consistent with decreased levels of $\mathrm{NAD}^{+} / \mathrm{NADH}$, mammary glands of NMU-treated rats showed decreased SIRT1 activity as compared to control rats. By contrast, SIRT1 activity was significantly higher in mammary glands of NMU-exposed rats maintained on
MSC-enriched diet (Fig. 4B). Importantly, the results from the in vivo studies were consistent with the findings in our in vitro studies. These results connect the effect of MSC on $\mathrm{NAD}^{+}$-dependent SIRT1 activity in the present study to its previously reported chemopreventive activity via the restoration of circadian expression of Per2 [13].

\section{MSC counteracts the effects of NMU on acetylation of BMAL1 and $\mathrm{H3} \mathrm{K} 9$ associated with $P$ er 2 gene promoter in rat mammary glands in vivo}

To further investigate the mechanisms by which the NMU- and MSC-induced alterations in SIRT1 activity modulate circadian gene expression, we used a Chromatin Immunoprecepitation (ChIP) assay to evaluate their effects on acetylation of BMAL1 and histones at E-box and Exon 1 within the Per2 promoter in vivo (Fig. 5A). The analysis showed that AcBMAL1 bound preferentially to the E-box relative to Exon 1 in Per2 promoter, indicating that circadian transcription of Per2 is associated with AcBMAL1 at Per2 promoter E-Box in mammary glands, as reported for other organs [32]. In controls, AcBMAL1 binding to the Per2 promoter was higher during the day (ZT0-12) than at night (ZT16-20), with the Per2 expression peaking at ZT16 (Fig. 5B \& Fig. 3). At day 30 post-exposure to NMU, we observed that binding of AcBMAL1 was delayed by $4-8$ hours, with peak binding at ZT12. Importantly, MSC advanced the phase of AcBMAL1 binding by $4-8$ hours to match that 
A

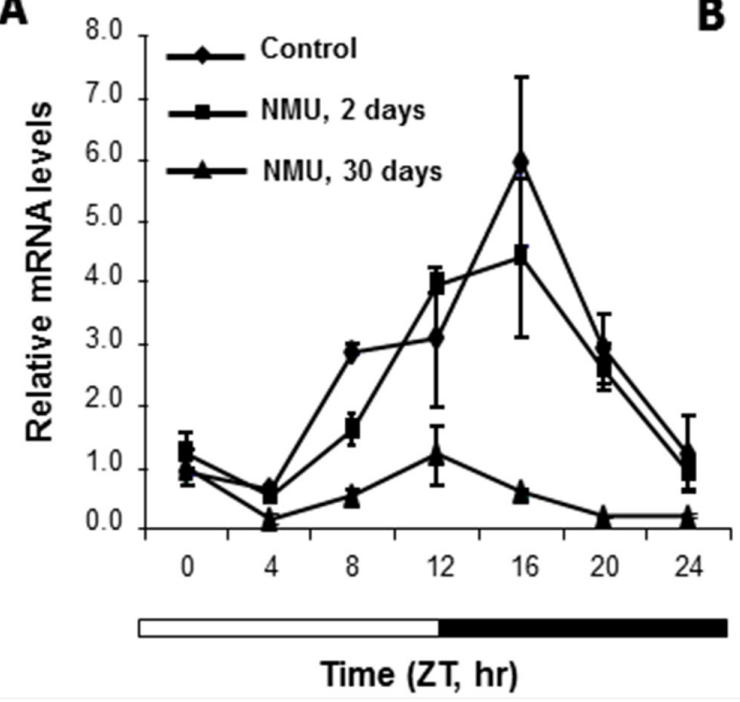

B

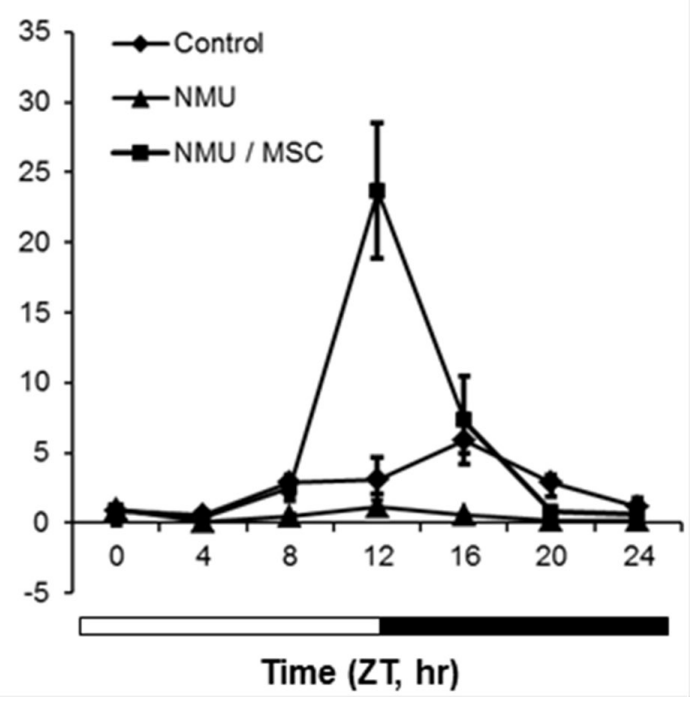

Figure 3: MSC restored the NMU-disrupted circadian expression of Per2 mRNA in mammary glands of NMU-treated rats in vivo. Three rats in each group were sacrificed every 4 hours over a 24-hour period, beginning at 7 AM. Per 2 mRNA expression levels were determined using RT-qPCR with total RNA samples extracted from rat mammary glands, and the results were analyzed with a comparative $\mathrm{Ct}$ method. Results were normalized with endogenous control, $\beta$-actin, and then with the expression level of the first sample at ZT0. X-axis: Zeitgeber Time (ZT), empty bar indicates light-on from ZT0 (7 AM) and black bar indicates light-off from ZT12 (7 PM); Y-axis: relative mRNA level, shown in mean $\pm \mathrm{SE}(n=3)$. A. NMU-treated rats were sacrificed at day 0 (control, diamond), 2 (square), or 30 (triangle) post-treatment. B. NMU-treated rats were maintained on control diet (triangle) or MSC-enriched diet (square) for 30 days post-exposure to NMU; rats untreated and maintained on control diet were used as control group (diamond).

A

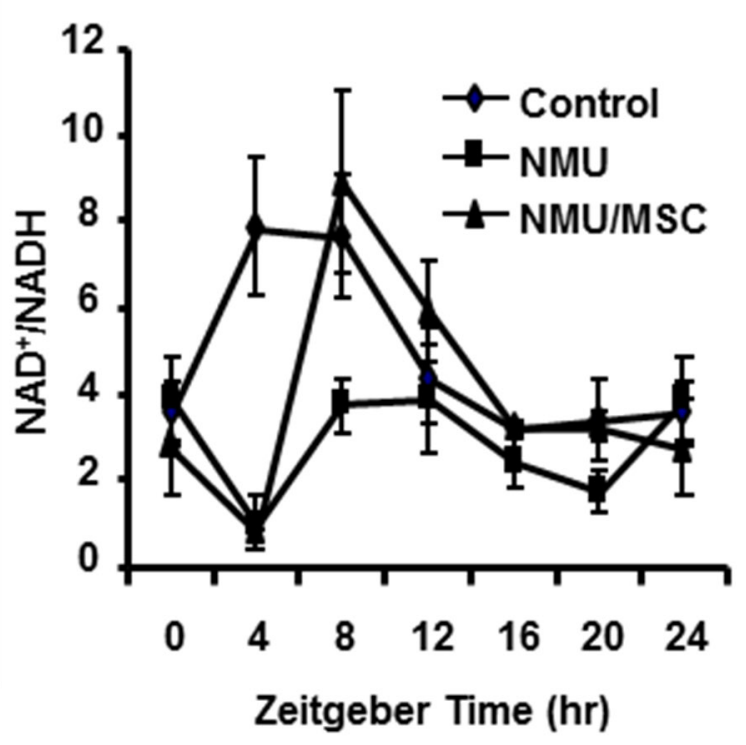

B

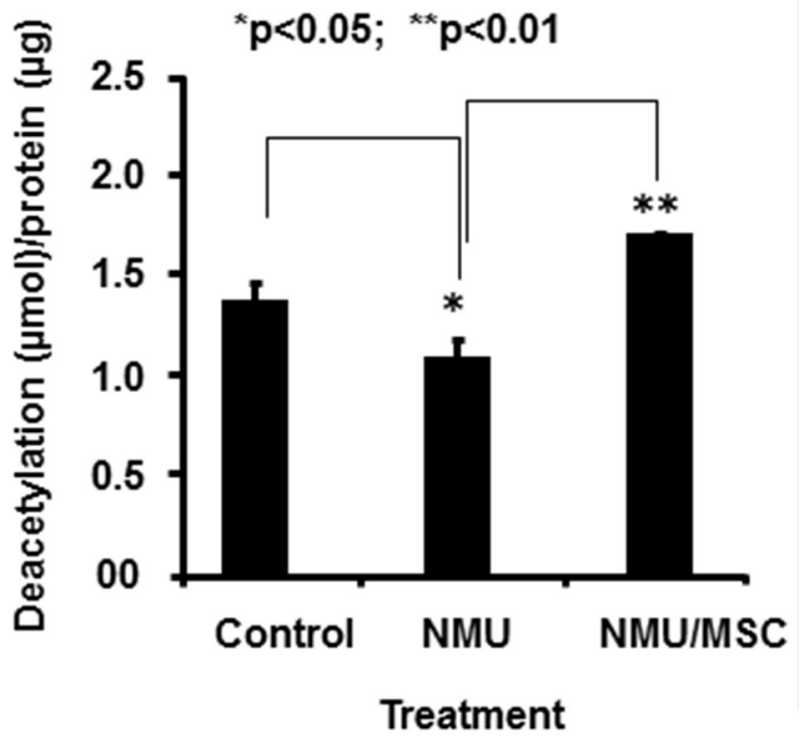

Figure 4: MSC reset the circadian oscillation of $\mathrm{NAD}^{+} / \mathrm{NADH}$ and increased SIRT1 activity in mammary glands of NMU-treated rats in vivo. On day 30 post-exposure to NMU, three rats per group (Control, NMU, or NMU/MSC) were sacrificed every 4 hours over a 24 hour period, beginning right after lights-on at 7 AM (ZT0). A. Tissue extracts prepared from mammary tissues of rats sacrificed at different time points over 24 hours subjected to $\mathrm{NAD}^{+} / \mathrm{NADH}$ quantification. X-axis: Zeitgeber time (ZT); Y-axis: $\mathrm{NAD}^{+/}$ $\mathrm{NADH}$, mean $\pm \mathrm{SE}(n=3)$. B. Total protein samples extracted from mammary tissues of rats sacrificed at ZT12 subjected to SIRT1 activity determination. X-axis: treatment group; Y-axis: SIRT1 activity, shown as deacetylated product ( $\mu$ mol)/protein $(\mu \mathrm{g})$, mean $\pm \operatorname{SE}(n=3)$. * And ** indicate statistical significance at $p \leq 0.05$ and $p \leq 0.01$, respectively. 
A

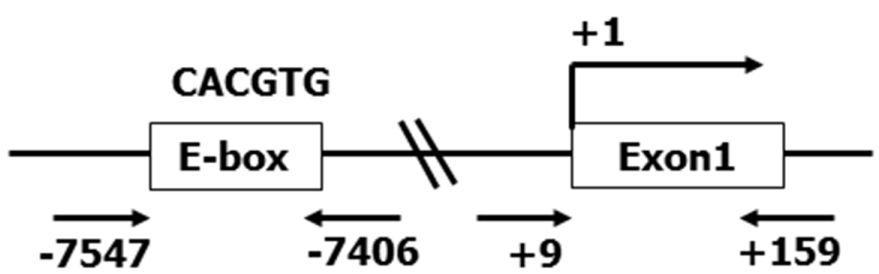

B

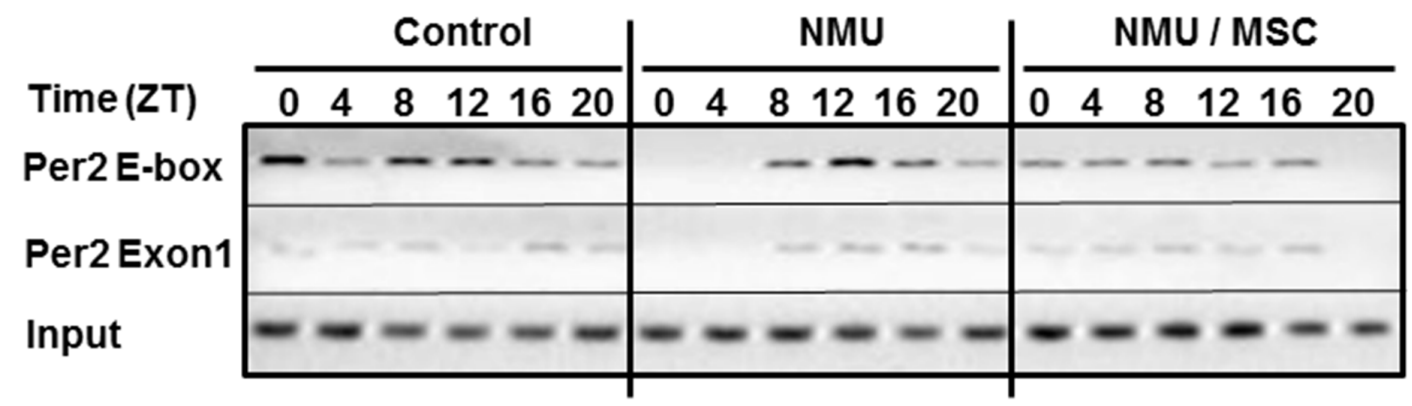

C

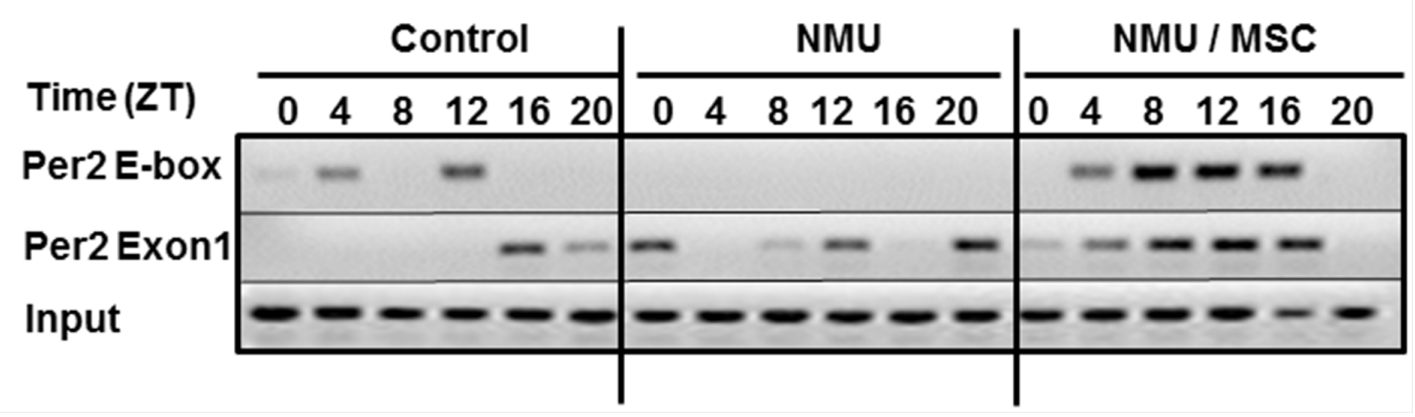

Figure 5: Dietary MSC counteracted the effects of NMU on acetylation of BMAL1 and H3K9 in Per2 promoter in mammary glands of NMU-treated rats in vivo. ChIP assay was performed with anti-AcBMAL1 or anti-AcH3K9 antibody and specific primer set against Per2 E-box or Exon1 in Per2 promoter. On day 30 post-exposure, three rats in each group were sacrificed every 4 hours over 24 hour, beginning at 7 AM (ZT0). Pooled mammary tissues from three rats per time per group subjected to ChIP. A. Schematic representation of the Per 2 promoter illustrates the regions of PCR amplicons against E-box binding motif and Exon1 in ChIP; B. AcBMAL1 levels; C. AcH3K9 levels. Upper, E-box; middle, Exon1; lower, input control.

of control cells, albeit with reduced binding, especially at ZT12-20 compared to that in NMU group (Fig. 5B). These observations indicated that MSC counteracts the effect of NMU on AcBMAL1 at E-box to induce Per2 mRNA expression in vivo (Fig. 5B \& Fig. 3).

Since acetylation status of histones was shown to be associated with the circadian transcription of Per2 and the acetylation process is also under circadian control [32], we next examined acetylation of histone 3 at lysine 9 (AcH3K9) on the E-box and Exon1 of the Per2 promoter after exposure to NMU and MSC. ChIP assay results showed that in controls, the peak of highest AcH3K9 level at E-box occurred at ZT12, four hours prior to the peak in Per2 mRNA; peak AcH3K9 level at Exon1 occurred at ZT16, corresponding to the peak Per2 mRNA transcription. In NMU-treated rats on control diet, there was no detectable AcH3K9 at the E-box and no rhythmic expression of Per2 mRNA expression; AcH3K9 was detectable at Exon1 although the change in level did not result in rhythmic pattern of Per2 mRNA expression. By comparison, NMU-treated rats maintained on MSC-enriched diet showed diurnal changes in $\mathrm{AcH} 3 \mathrm{~K} 9$ at both Exon1 and E-box sites, with peak values at ZT 8-12 (Fig. 5C \& Fig. 3). These results suggest that circadian pattern of AcH3K9 at the E-box is temporally correlated with the rhythm, while AcH3K9 at Exon1 is correlated with the change of level in Per2 mRNA expression (Fig. 5C \& Fig. 3). While NMU completely abolished AcH3K9 at E-box and circadian rhythm of Per2 mRNA expression, MSC-enriched diet restored circadian patterns of AcH3K9 in promoter regions and enhanced rhythmic mRNA expression of Per 2 in NMU treated animals.

\section{DISCUSSION}

Both epidemiology and animal studies have indicated that selenium reduces the incidence of various cancers, stimulating several large-scale intervention trials 
using various organic selenium compounds $[16,34]$. Unfortunately, none of these interventions showed protective effects of selenium compounds, highlighting the need for defining and matching the mechanistic underpinnings with compounds that target patients with specific exposures and/or risk factors. The present study investigated the mechanism by which MSC restores circadian gene expression, with the goal of using mechanistic insights to develop intervention strategies to reduce the risk of breast cancer associated with exposures that disturb circadian rhythm.

A wide array of metabolic and physiological processes display daily oscillations $[35,36]$, and an interplay exists between circadian clocks and metabolic rhythms in all organisms [37]. Metabolic rhythms connect the circadian clock via cycles of epigenetic modification. Two of these, the $\mathrm{NAD}^{+}$and acetylation cycles, affect the amplitude of circadian gene expression [32]. Correlation between DNA damage-associated $\mathrm{NAD}^{+}$depletion and decrease of SIRT1 activity in older rats suggested that $\mathrm{NAD}^{+}$is important for cancer prevention and longevity [38]. The repair of single-strand DNA breaks by base excision is facilitated by poly-(ADP-ribose) polymerase (PARP), which uses $\mathrm{NAD}^{+}$as a substrate. Since $\mathrm{NAD}^{+}$also serves as an important redox carrier to power oxidative phosphorylation and ATP production, prolonged activation of PARP depletes $\mathrm{NAD}^{+}$and causes cell death [39].

We hypothesize that exposure to DNA-damaging agents depletes intracellular $\mathrm{NAD}^{+}$and decreases SIRT1 activity, attenuating circadian rhythm, reducing the ATM/CHEK2-mediated DNA repair, which in turn activates PARP to further deplete $\mathrm{NAD}^{+}$. NMU is a potent alkylating agent. Base excision repair is the principal mechanism by which mammalian cells repair alkylated DNA. Depleting of cellular NAD ${ }^{+}$is therefore a plausible mechanism by which NMU could ablate epigenetic regulation of circadian genes. Excision repair-induced depletion of NAD ${ }^{+}$could decrease SIRT1 activity, leading to increased AcBMAL1 at the corresponding time point and repressed circadian expression of Per 2 and CCGs, including DNA repair genes and tumor suppressor genes [13]. This hypothesis is supported by our observation from both in vitro and in vivo assays. Mammary cell death and inflammation after NMU exposure could also contribute to the disruption of circadian rhythm in vivo at the early time point [40], but are unlikely to precipitate the observed progressive and persistent circadian disruption over 30 days.

Selenium compounds protect cells against peroxynitrite-induced DNA damage through glutathionemediated redox cycling and enhance cellular defenses against oxidative DNA damage [21]. Accordingly, selenium supplementation decreased oxidative DNA damage and reduced breast cancer risk in recent intervention trials [23]. The selenium-modulated cycling of GSH/GSSG is coupled to $\mathrm{NADP}^{+} / \mathrm{NADPH}$ and $\mathrm{NAD}^{+} /$ $\mathrm{NADH}$, suggesting that selenium affects levels of NAD ${ }^{+}$ metabolites through its antioxidant properties [21]. We found that MSC regulates redox cycling $\left(\mathrm{NAD}^{+} / \mathrm{NADH}\right)$, increasing $\mathrm{NAD}^{+}$-dependent SIRT1 activity and expression of the major CGs, Per2. Since the expression of $\sim 10 \%$ of genes involved in DNA repair and cell proliferation is controlled by circadian rhythm [2], MSC-induced circadian expression might enhance ATM/CHEK2mediated DNA repair to reduce DNA damage and prevent $\mathrm{NAD}^{+}$depletion. Selenium compounds have also been shown to activate ATM-mediated repair in response to genotoxic and oxidative stresses, which could contribute to prevent $\mathrm{NAD}^{+}$depletion and reset circadian rhythm, enhancing barriers to tumorigenisis [22].

Further mechanistic studies indicated that the MSCinduced increase of SIRT1 activity correlated temporally with decreased AcBMAL1 at the E-box element of Per 2 promoter. These changes correlated with enhanced circadian Per 2 transcription, supporting the contention that SIRT1 is required for circadian transcription of major CGs (e.g., Per2). These findings are consistent with previous studies showing that SIRT1 uses NAD ${ }^{+}$ to remove acetyl groups from BMAL1, decreasing AcBMAL1 and leading to enhanced CLOCK/BMAL1 binding to E-boxes, acetylation of $\mathrm{H} 3$ and transcription of Per $[33,41]$. Alternatively, enhanced deacetylation and degradation of PER2 protein by increased SIRT1 activity could also be a mechanism underlying the restoration of rhythmic Per2 mRNA expression [42]. Additional studies will be required to fully understand the mechanism by which the reduced (or enhanced) NAD ${ }^{+}$-SIRT1 activity caused disruption (or restoration) of rhythmic expression of Per 2 mRNA in mammary epithelial cells.

Significantly, we observed similar results in mammary cells both in vitro and in vivo. By contrast, in vitro studies in mouse embryo fibroblasts indicated that SIRT1 inhibitors actually enhanced the rhythmic expression of the $D b p$ gene during the circadian first cycle post serum shock [33]. We detected a similar effect when mammary epithelial cells were treated with NMU or SIRT1 inhibitors in vitro. These observations suggest that the initial response to agents that perturb circadian regulation may be induction of compensatory mechanisms. However, our in vitro results indicated that despite this initial adaptive response, cells treated with NMU or SIRT1 inhibitors immediately showed dampening of subsequent circadian cycles. The inability to reestablish a second cycle suggests that imbalance in the circadian clock machinery compromises amplitude control and/or the cells were unable to sustain the initial compensatory response [43]. In the case of genotoxicants, this could be due to depletion of intracellular $\mathrm{NAD}^{+}$by DNA repair processes. Increase of $\mathrm{NAD}^{+} / \mathrm{NADH}$ by $\mathrm{MSC}$ could prevent depletion of intracellular $\mathrm{NAD}^{+}$, allowing the circadian gene expression to persist in subsequent cycles. Nonetheless, further investigations are needed to address these differences. 
It is important to note that the regulation of circadian gene expression can vary significantly among cell types, species and even strains of mice $[44,45]$. Of particular note is that regulation of circadian gene expression is independent of melatonin in many mouse strains [45]. The absence of the melatonin-mediated circadian control leads to a compensatory substitution of energy balance/ food intake as a mediator of circadian regulation [46]. As a result, the primary circadian regulatory mechanisms and responses to stressors may show commensurate variations.

In our studies, MSC-induced SIRT1 activity was correlated with restoration and enhancement of circadian histone acetylation (AcH3K9). These findings are consistent with previous studies showing that inhibition of SIRT1 activity in vitro abolished rhythm of AcK3K9 at the E-box motif of the circadian outcome gene, $D b p$ [33]. In addition, the rhythmic AcH3K9 not only regulates the rhythmic mRNA expression of Per2 gene, but is also controlled by the circadian clock [31]. The enhanced AcH3K9 rhythm might thus be regulated by increased circadian rhythm that was modulated by decreased-AcBMAL1 resulting from increased $\mathrm{NAD}^{+}$dependent SIRT1 activity by MSC. Alternatively, the inhibitory effect of MSC on other histone deacetylases could also contribute to the increased level of AcH3K9 in vivo [26]. These results suggest that enhancement of $\mathrm{NAD}^{+}$-dependent SIRT1 activity by MSC can restore circadian gene expression following carcinogen exposure. The resulting increase in molecular circadian oscillation may resynchronize the $\mathrm{AcH} 3 \mathrm{~K} 9$ cycling in the promoters of CGs and CCGs to further amplify the rhythmic gene expression (Fig. 6). Regardless of a precise molecular mechanism, our observation on the ability of selenium to modulate circadian transcriptional activity is supported by a previous report indicating that selenium modulates the circadian clock to protect mice from the toxicity of a chemotherapeutic drug [18].

Together with our previous findings in chemoprevention studies $[13,15]$, these results indicate that MSC enhances $\mathrm{NAD}^{+} / \mathrm{NADH}$ oscillation and SIRT1 activity to increase circadian expression of genes involved in DNA repair and tumor suppression, contributing to early barrier to tumorigenesis. Although the role of SIRT1 gene in carcinogenesis remains controversial [47], studies in various in vitro studies and in vivo models have found a significant association between the increases in $\mathrm{NAD}^{+}$ level and SIRT1 activity by fasting, exercise, and other chemopreventive regimens and the prevention of agingrelated diseases, including cancer and metabolic syndrome [48-50]. Increased SIRT1 activity may prevent the early stage pathogenesis by restoring or enhancing circadian rhythms. These findings suggest that the ability of various SIRT1 activating compounds, including plant polyphenols, niacin vitamins, and nicotinamide riboside, to prevent

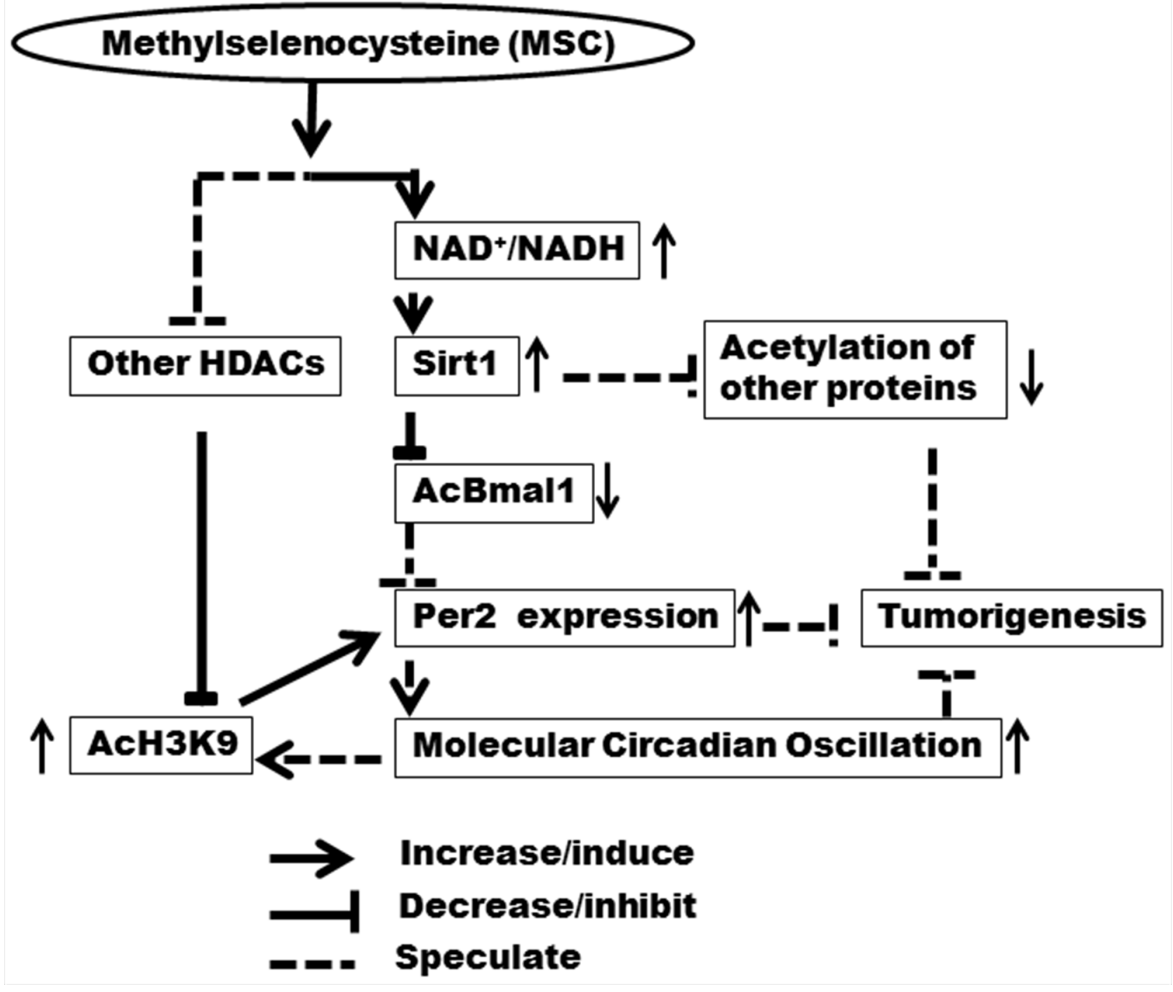

Figure 6: Mechanistic diagram of $\mathrm{NAD}^{+} / \mathrm{NADH}$ and SIRT1 in regulation of circadian rhythm by MSC. Enhancement of $\mathrm{NAD}^{+}$-dependent SIRT1 activity by MSC restores circadian rhythm via restoring epigenetic regulation of Per2 expression, which may contribute to chemopreventive activity of MSC at the early stage of tumorigenesis. 
stress-related disease processes may be partially mediated through their effects on circadian rhythm [51]. The ability of dietary MSC to modulate circadian rhythm by enhancing SIRT1 activity may have therefore significant implication in chemoprevention of cancer and other agingrelated chronic diseases. Testing of a large panel of cell lines and animal models would be needed to determine how universal the restoration effect of dietary MSC on circadian rhythm disrupted by environmental factors is. Further studies are warranted to assess whether the chemopreventive potential of MSC can be enhanced when used in combination with other agents that prevent $\mathrm{NAD}^{+}$ depletion and activate SIRT1 activity during the early stage of tumorigenesis.

\section{MATERIALS AND METHODS}

\section{Cell culture and treatment}

Immortalized, non-tumorigenic human mammary epithelial cell line (MCF10A) was purchased from the American Type Culture Collection (ATCC), where cells were cytogenetically tested and authenticated with short tandem repeat analysis before freezing. Each vial of frozen cells was thawed and maintained in culture for a maximum of 8 weeks. Cells were cultured in mammary epithelial cell growth medium (MEGM) (Lonza), containing mammary epithelial basal medium (MEBM) and growth supplements provided in SigleQuots Kit (Lonza) (including $0.4 \%$ bovine pituitary extract, $0.1 \%$ insulin, $0.1 \%$ hydrocortisone, $0.1 \%$ human epidermal growth factors, and $0.05 \%$ gentamycin sulfate and $0.05 \%$ amphotericin-B). Cholera toxin (Sigma) was also added to MEGM at a final concentration of $100 \mathrm{ng} / \mathrm{ml}$. Cells were incubated at $37^{\circ} \mathrm{C}, 95 \%$ humidity and $5 \% \mathrm{CO}_{2}$.

For NAD ${ }^{+} / \mathrm{NADH}$ and SIRT1 activity assays, cells were treated with NMU $(0.25$ or $0.50 \mathrm{mM})$ or vehicle control $(0.1 \% \mathrm{DMSO})$ for 1 hour at $37^{\circ} \mathrm{C}$. After washing with 1XPBS, cells were treated with MSC (6.3 or $12.5 \mu \mathrm{M})$ or vehicle control $(0.1 \%$ ethanol) for 72 hours.

\section{Cellular circadian rhythm assay}

A fragment (947 bp) of the promoter region of human PER2 ( $h P E R 2 P$ ) containing 3 of BMAL1 binding motifs (CAC/TGTG) was obtained from a plasmid, $\mathrm{pLS}[\mathrm{hPER} 2 \mathrm{P} / \mathrm{rLuc} / \mathrm{Puro}]$ (LightSwitch Genomics). hPER2P was subcloned into destabilized firefly luciferase (dLuc) vector with neomycin selection gene [pGL(Luc2P/ $\mathrm{Neo})$ (Promega), producing a pGL[hPER2P(Luc2P/Neo)] construct. MCF10A cells were seeded in 35-mm dishes at $2 \times 10^{5}$ cells per dish and transfected with $1 \mu \mathrm{g}$ of vector using FuGene $\mathrm{HD}^{\mathrm{TM}}$ transfection reagent (LightSwitch Genomics). After 48 hours post-transfection, cells were starved from growth factors in MEBM for 24 hours. After synchronization with 50\% horse serum (HS) (Invitrogen) for 2 hours, cells were treated with $0.25 \mathrm{mM}$ or $0.5 \mathrm{mM}$
NMU, 20 nM EX527 (a SIRT1-specific inhibitor, Sigma), or $1 \mu \mathrm{M}$ cambinol (inhibit both SIRT1 and SIRT2, Sigma) for 1 hour in MEBM. After washing with PBS, recording medium [MEBM supplemented with $20 \%$ of normal concentrations of growth supplements, $6.5 \mathrm{mM}$ sodium bicarbonate, $10 \mathrm{mM}$ HEPES buffer ( $\mathrm{pH} 7.2), 0.1 \mathrm{mM}$ Luciferin (Promega), and 50 units/ml penicillin and $50 \mu \mathrm{g} / \mathrm{ml}$ streptomycin] containing $12.5 \mu \mathrm{M}$ MSC alone, or in combination with $20 \mathrm{nM}$ EX527 or $1 \mu \mathrm{M}$ cambinol was added. Plates were sealed with a sterile glass cover slide using silicon grease and subjected to continuous monitoring by an LumiCycle $32^{\mathrm{TM}}$ (Actimetric). Stably transfected MCF10A/PER2-dLuc cells selected with $1000 \mu \mathrm{g} / \mathrm{ml}$ of G418 (Gibco) were treated with NMU at $0.5,1$, or $2 \mathrm{mM}, \mathrm{EX} 527$ at $40 \mathrm{nM}$, or Cambinol at $2.0 \mu \mathrm{M}$ for 1 hour after synchronization with $50 \% \mathrm{HS}$, and then the cells were incubated in recording medium containing $12.5 \mu \mathrm{M}$ of MSC and monitored by LumiCycle for 4-5 days. By using LumiCycle Analysis Software (Actimerics), the data were detrended (running average) and then best-fits to a sine wave were estimated by a Levenberg-Marquardt algorithm for measurement of period, phase, amplitude, and damping rate as reported previously [52]. All treatment concentrations used were lower than LC30 after incubation for the time indicated. All experiments were conducted three times and the representative results were presented.

\section{Animal treatment and sample collection}

Experiments were performed in AAALAC accredited facilities at Rutgers, The State University of New Jersey using protocols approved by our Institutional Animal Care and Use Committee. Female Fisher (F344) rats (Harlan Laboratories) were acclimatized to a powdered ration (Tekland). Rats were maintained on the powdered diet (i.e., standard AIN-76A diet containing $0.01 \mathrm{ppm}$ selenium as sodium selenite) for one week. The MSC-enriched diet was produced by admixing $L$-Se-methylselenocysteine (Selenium Technologies) with the control diet to a concentration of $3 \mathrm{ppm}$ selenium. Animals were housed under controlled conditions with a 12 hour light/12 hour dark cycle. Zeitgeber Time 0 (ZT 0) was set at 7 AM (light on); ZT12 was set at 7 PM (light off).

NMU (Sigma) was dissolved in acidified saline ( $\mathrm{pH} \mathrm{5)}$ to a concentration of $10 \mathrm{mg} / \mathrm{ml}$ immediately before injection. For time course studies, 63 female F344 rats (aged $55 \pm 2$ days, 155-175 g) treated with NMU by a single intra-peritoneal (i.p.) injection $(50 \mathrm{mg} / \mathrm{kg}$ body weight), were randomized to 3 groups (21 rats per group). Groups 1, 2, and 3 were sacrificed at days 0, 2, and 30 post-exposure, respectively. For mechanistic studies, 42 NMU-treated rats were randomized into two groups of 21 animals and maintained on control diet or MSCenriched diet for 30 days. Twenty-one vehicle controls maintained on standardized diet served as the control group. Three rats per group were sacrificed by $\mathrm{CO}_{2}$ 
asphyxiation every 4 hours over a 24-hour period, beginning at 7 AM (ZT0). All mammary glands at each side of individual rats were carefully dissected, combined into a pool of left or right mammary gland tissue sample. Tissue samples were snap-frozen on dry ice, and then stored at $-80^{\circ} \mathrm{C}$.

\section{$\mathbf{N A D}^{+} / \mathbf{N A D H}$ quantification}

Assays were performed with frozen rat mammary gland samples or cultured cells. Frozen right-side mammary gland samples $(\sim 50 \mathrm{mg})$ from 3 rats per group per time were used for $\mathrm{NAD}^{+} / \mathrm{NADH}$ assay. Tissue samples or cell pellets were homogenized, extracted, and filtered using $10 \mathrm{Kd}$ spin column (BioVison) to remove enzymes that rapidly consume $\mathrm{NADH}$. NAD ${ }^{+} / \mathrm{NADH}$ ratios were determined using $\mathrm{NAD}^{+} /$ NADH Quantification Kit ${ }^{\mathrm{TM}}$ (BioVision) according to the manufacturer instruction. The $\mathrm{NAD}^{+} / \mathrm{NADH}$ was calculated with the formulation (NADt-NADH)/NADH, where NADt is total of NADH and $\mathrm{NAD}^{+}$. Three independent samples per group per time were analyzed in triplicate.

\section{SIRT1 activity assay}

Total protein extracts were prepared from a small piece $(\sim 50 \mathrm{mg})$ of tissue from right-side mammary gland of individual rats sacrificed at ZT12 on the day 30 post-exposure, or from cultured cells with RIPA buffer. SIRT1 deacetylase activity was determined with SIRT1 Fluorimetric Drug Discovery Kits ${ }^{\mathrm{TM}}$ (Enzo Life Sciences). Briefly, initial deacetylation rates of SIRT1 were determined at 1 unit human recombinant SIRT1 enzyme, $25 \mu \mathrm{M}$ deacetylase substrate, and $25 \mu \mathrm{M} \mathrm{NAD}^{+}$ $\left(37^{\circ} \mathrm{C}\right)$ in the absence (control) or presence of $10 \mu \mathrm{l}$ of extracted protein. Fluorescence signal was measured with a microplate reader at $360 \mathrm{~nm}$ excitation and $460 \mathrm{~nm}$ emission wavelengths. Standard curve was produced with serially diluted-deacetylation standard. Activity was normalized to protein concentration and expressed as deacetylated product $(\mu \mathrm{mol}) /$ protein $(\mu \mathrm{g})$. Three independent samples per group were analyzed in triplicate.

To determine if NMU and MSC affected SIRT1 activity directly, we also performed SIRT1 activity assay with different concentrations of NMU $(0,0.25,0.5$, $1 \mathrm{mM})$ or $\operatorname{MSC}(0,6.3,12.5,25 \mu \mathrm{M})$ in the presence of purified human recombinant SIRT1 enzyme but absence of extracted tissue protein ex vivo.

\section{Quantitative real-time RT-PCR}

Total RNA was extracted from a small piece $(\sim 50 \mathrm{mg})$ of frozen tissue from right-side mammary glands of rats sacrificed on days 0,2 , and 30 post-exposure to NMU with or without MSC-enriched diet. Per 2 mRNA expression levels were determined using real-time quantitative RT-PCR as described previously [13].

\section{Chromatin immunoprecipitation (ChIP) assay}

Pooled frozen right-side mammary tissue samples from three rats (100 mg mammary gland per rat) per group at each time point were used for ChIP assay. Frozen tissues were pulverized and cross-linked with $1 \%$ formaldehyde, followed by quenching with $125 \mathrm{mM}$ glycine. Cell pellets were homogenized with cold cell lysis buffer containing protease inhibitor cocktails I \& II (Sigma) and processed using EZ-ChIP ${ }^{\mathrm{TM}}$ kits (Millipore). Briefly, nuclear and membrane pellets were lysed and sonicated to chromatin fragments of $\sim 200-1000$ base pairs. Cross-linked chromatin was pre-cleared and incubated with anti-acetylated BMAL1 (AcBMAL1) antibody (Santa Cruz Biotech) or anti- acetylated H3K9 (AcH3K9) antibody (Santa Cruz Biotech) at $4^{\circ} \mathrm{C}$ overnight. Normal rabbit IgG served as negative control and anti-RNA polymerase II as positive control. After protein-DNA cross-links were reversed; resolved, purified DNA was used for PCR. PCR was performed with primers targeting the E-box (CACGTG) (sense, 5'-AGCTGGGCTATAGAGGTGCTGA-3'; antisense, 5'-CACCGTCTCTGTGGCACGT-3') or Exon1 region (sense, 5'- AATCAGCTTTCCAAACTGGTTCC-3'; anti-sense, 5'-TGGAGCAGTCACGTCATCCTT-3') in the Per 2 promoter. PCR conditions were as follows: 1 cycle at $95^{\circ} \mathrm{C}$ for $1.5 \mathrm{~min}, 35$ cycles of inactivation at $95^{\circ} \mathrm{C}$ for $45 \mathrm{~s}$, annealing at $60^{\circ} \mathrm{C}$ for $60 \mathrm{~s}$, and extension at $72^{\circ} \mathrm{C}$ for $60 \mathrm{~s}$, and 1 final cycle for extension at $72^{\circ} \mathrm{C}$ for $5 \mathrm{~min}$. PCR products were resolved by electrophoresis and photographed.

\section{Statistical analyses}

Animal number $N=3$ was used in vivo studies. All experiments were performed in triplicate in in vitro studies. Intergroup differences were evaluated using oneway ANOVA, followed by Tukey's post-hoc test. We used alpha $=0.05$ or 0.01 as the level of significance for hypothesis testing.

\section{ACKNOWLEDGMENTS}

We thank Ms. Christal Lewis and Mr. Rohit Rangroo for experimental assistance.

\section{CONFLICTS OF INTEREST}

No conflicts to disclose.

\section{GRANT SUPPORT}

National Institutes of Health (U19ES011387 and P30ES005022) and V Foundation Grant for Cancer Research to H.Z. and Society of Toxicology - Colgate Palmolive Grant for Alternative Research to M.F. 


\section{REFERENCES}

1. Fu L, Lee CC. The circadian clock: pacemaker and tumour suppressor. Nat Rev Cancer. 2003; 3:350-361.

2. Chen-Goodspeed M, Lee CC. Tumor suppression and circadian function. J Biol Rhythms. 2007; 22:291-298.

3. Balsalobre A. Clock genes in mammalian peripheral tissues. Cell Tissue Res. 2002; 309:193-199.

4. Mackey SR. Biological rhythms workshop IA: Molecular Basis of Rhythms Generation In: Stillman B SD, Grodzicker T, ed. Cold Spring Harbor Symposia on Quantitative Biology (Cold Spring Harbor: Cold Spring Harbor Laboratory Press). 2007; pp. 7-19.

5. Rana S, Mahmood S. Circadian rhythm and its role in malignancy. J Circadian Rhythms. 2010; 8:3.

6. Chen Z, Odstrcil EA, Tu BP, McKnight SL. Restriction of DNA replication to the reductive phase of the metabolic cycle protects genome integrity. Science. 2007; 316:1916-1919.

7. Destici E, Oklejewicz M, Nijman R, Tamanini F, Van Der Horst GT. Impact of the circadian clock on in vitro genotoxic risk assessment assays. Mutation Res. 2009; 680:87-94.

8. Oklejewicz M, Destici E, Tamanini F, Hut RA, Janssens R, Van Der Horst GT. Phase resetting of the mammalian circadian clock by DNA damage. Curr Biol. 2008; 18:286-291.

9. Haus EL, Smolensky MH. Shift work and cancer risk: potential mechanistic roles of circadian disruption, light at night, and sleep deprivation. Sleep Medicine Reviews. 2013; 17:273-284.

10. Fu L, Kettner NM. The circadian clock in cancer development and therapy. Prog Mol Biol Transi Sci. 2013; 119:221-282.

11. Fu A, Leaderer D, Zheng T, Hoffman AE, Stevens RG, Zhu Y. Genetic and epigenetic associations of circadian gene TIMELESS and breast cancer risk. Mol Carcinogenesis. 2012; 51:923-929.

12. Mao Y, Fu A, Hoffman AE, Jacobs DI, Jin M, Chen K, Zhu Y. The circadian gene CRY2 is associated with breast cancer aggressiveness possibly via epigenomic modifications. Tumour Biol. 2015; 36:3533-3539.

13. Fang MZ, Zhang X, Zarbl H. Methylselenocysteine resets the rhythmic expression of circadian and growth-regulatory genes disrupted by nitrosomethylurea in vivo. Cancer Prev Res (Phila). 2010; 3:640-652.

14. Gery S, Virk RK, Chumakov K, Yu A, Koeffler HP. The clock gene Per2 links the circadian system to the estrogen receptor. Oncogene. 2007; 26:7916-7920.

15. Zhang $\mathrm{X}$, Zarbl $\mathrm{H}$. Chemopreventive doses of methylselenocysteine alter circadian rhythm in rat mammary tissue. Cancer Prev Res (Philadelphia, Pa.). 2008; $1: 119-127$.
16. Jackson MI, Combs GF, Jr. Selenium and anticarcinogenesis: underlying mechanisms. Curr Opin Clin Nutr Metab Care. 2008; 11:718-726.

17. El-Bayoumy K, Upadhyaya P, Sohn OS, Rosa JG, Fiala ES. Synthesis and excretion profile of 1,4-[14C] phenylenebis(methylene)selenocyanate in the rat. Carcinogenesis. 1998; 19:1603-1607.

18. $\mathrm{Hu} \mathrm{Y}$, Spengler ML, Kuropatwinski KK, ComasSoberats M, Jackson M, Chernov MV, Gleiberman AS, Fedtsova N, Rustum YM, Gudkov AV, Antoch MP. Selenium is a modulator of circadian clock that protects mice from the toxicity of a chemotherapeutic drug via upregulation of the core clock protein, BMAL1. Oncotarget. 2011;2:1279-1290.

19. Cao S, Durrani FA, Toth K, Rustum YM. Se-methylselenocysteine offers selective protection against toxicity and potentiates the antitumour activity of anticancer drugs in preclinical animal models. British Journal of Cancer. 2014; 110:1733-1743.

20. Ganther HE. Selenium metabolism, selenoproteins and mechanisms of cancer prevention: complexities with thioredoxin reductase. Carcinogenesis. 1999; 20:1657-1666.

21. De Silva V, Woznichak MM, Burns KL, Grant KB, May SW. Selenium redox cycling in the protective effects of organoselenides against oxidant-induced DNA damage. Journal of the American Chemical Society. 2004; 126:2409-2413.

22. Wu M, Kang MM, Schoene NW, Cheng WH. Selenium compounds activate early barriers of tumorigenesis. J Biol Chem. 285:12055-12062.

23. Dziaman T, Huzarski T, Gackowski D, Rozalski R, Siomek A, Szpila A, Guz J, Lubinski J, Wasowicz W, Roszkowski K, Olinski R. Selenium supplementation reduced oxidative DNA damage in adnexectomized BRCA1 mutations carriers. Cancer Epidemiol Biomarkers Prev. 2009; 18:2923-2928.

24. Youn BW, Fiala ES, Sohn OS. Mechanisms of organoselenium compounds in chemoprevention: effects on transcription factor-DNA binding. Nutr Cancer. 2001; 40:28-33.

25. Smith ML, Lancia JK, Mercer TI, Ip C. Selenium compounds regulate $\mathrm{p} 53$ by common and distinctive mechanisms. Anticancer Res. 2004; 24:1401-1408.

26. Xiang N, Zhao R, Song G, Zhong W. Selenite reactivates silenced genes by modifying DNA methylation and histones in prostate cancer cells. Carcinogenesis. 2008; 29:2175-2181.

27. Fiala ES, Staretz ME, Pandya GA, El-Bayoumy K, Hamilton SR. Inhibition of DNA cytosine methyltransferase by chemopreventive selenium compounds, determined by an improved assay for DNA cytosine methyltransferase and DNA cytosine methylation. Carcinogenesis. 1998; 19:597-604. 
28. Ip C, Lisk DJ, Thompson HJ. Selenium-enriched garlic inhibits the early stage but not the late stage of mammary carcinogenesis. Carcinogenesis. 1996; 17:1979-1982.

29. Ellis L, Atadja PW, Johnstone RW. Epigenetics in cancer: targeting chromatin modifications. Mol Cancer Ther. 2009; 8:1409-1420.

30. Crosio C, Cermakian N, Allis CD, Sassone-Corsi P. Light induces chromatin modification in cells of the mammalian circadian clock. Nat Neurosci. 2000; 3:1241-1247.

31. Etchegaray JP, Lee C, Wade PA, Reppert SM. Rhythmic histone acetylation underlies transcription in the mammalian circadian clock. Nature. 2003; 421:177-182.

32. Doi M, Hirayama J, Sassone-Corsi P. Circadian regulator CLOCK is a histone acetyltransferase. Cell. 2006; 125:497-508.

33. Nakahata Y, Kaluzova M, Grimaldi B, Sahar S, Hirayama J, Chen D, Guarente LP, Sassone-Corsi P. The NAD+-dependent deacetylase SIRT1 modulates CLOCK-mediated chromatin remodeling and circadian control. Cell. 2008; 134:329-340.

34. Lippman SM, Klein EA, Goodman PJ, Lucia MS, Thompson IM, Ford LG, Parnes HL, Minasian LM, Gaziano JM, Hartline JA, Parsons JK, Bearden JD, 3rd, Crawford ED, Goodman GE, Claudio J, Winquist E, et al. Effect of selenium and vitamin $\mathrm{E}$ on risk of prostate cancer and other cancers: the Selenium and Vitamin E Cancer Prevention Trial (SELECT). Jama. 2009; 301:39-51.

35. Storch KF, Lipan O, Leykin I, Viswanathan N, Davis FC, Wong WH, Weitz CJ. Extensive and divergent circadian gene expression in liver and heart. Nature. 2002; 417:78-83.

36. Ueda HR, Chen W, Adachi A, Wakamatsu H, Hayashi S, Takasugi T, Nagano M, Nakahama K, Suzuki Y, Sugano S, Iino M, Shigeyoshi Y, Hashimoto S. A transcription factor response element for gene expression during circadian night. Nature. 2002; 418:534-539.

37. Wijnen H, Young MW. Interplay of circadian clocks and metabolic rhythms. Annu Rev Genet. 2006; 40:409-448.

38. Braidy N, Guillemin GJ, Mansour H, Chan-Ling T, Poljak A, Grant R. Age related changes in NAD+ metabolism oxidative stress and Sirt1 activity in wistar rats. PloS one. 2011; 6:e19194.

39. Virag L. Structure and function of poly(ADP-ribose) polymerase-1: role in oxidative stress-related pathologies. Curr Vasc Pharmacol. 2005; 3:209-214.

40. Haimovich B, Calvano J, Haimovich AD, Calvano SE, Coyle SM, Lowry SF. In vivo endotoxin synchronizes and suppresses clock gene expression in human peripheral blood leukocytes. Crit Care Med. 2010; 38:751-758.

41. Belden WJ, Dunlap JC. SIRT1 is a circadian deacetylase for core clock components. Cell. 2008; 134:212-214.
42. Asher G, Gatfield D, Stratmann M, Reinke H, Dibner C, Kreppel F, Mostoslavsky R, Alt FW, Schibler U. SIRT1 regulates circadian clock gene expression through PER2 deacetylation. Cell. 2008; 134:317-328.

43. Chen Z, Yoo SH, Takahashi JS. Small molecule modifiers of circadian clocks. Cellular and molecular life sciences: CMLS. 2013; 70:2985-2998.

44. Sladek M, Polidarova L, Novakova M, Parkanova D, Sumova A. Early chronotype and tissue-specific alterations of circadian clock function in spontaneously hypertensive rats. PLoS One. 2012; 7:e46951.

45. Roseboom PH, Namboodiri MA, Zimonjic DB, Popescu NC, Rodriguez IR, Gastel JA, Klein DC. Natural melatonin 'knockdown' in C57BL/6J mice: rare mechanism truncates serotonin N-acetyltransferase. Brain Res Mol Brain Res. 1998; 63:189-197.

46. Muhlbauer E, Gross E, Labucay K, Wolgast S, Peschke E. Loss of melatonin signalling and its impact on circadian rhythms in mouse organs regulating blood glucose. Eur J Pharmacol. 2009; 606:61-71.

47. Elangovan S, Ramachandran S, Venkatesan N, Ananth S, Gnana-Prakasam JP, Martin PM, Browning DD, Schoenlein PV, Prasad PD, Ganapathy V, Thangaraju M. SIRT1 is essential for oncogenic signaling by estrogen/ estrogen receptor alpha in breast cancer. Cancer Res. 2011; 71:6654-6664.

48. Hayashida S, Arimoto A, Kuramoto Y, Kozako T, Honda S, Shimeno H, Soeda S. Fasting promotes the expression of SIRT1, an NAD+ -dependent protein deacetylase, via activation of PPARalpha in mice. Mol Cell Biochem. 2010; 339:285-292.

49. Koltai E, Szabo Z, Atalay M, Boldogh I, Naito H, Goto S, Nyakas C, Radak Z. Exercise alters SIRT1, SIRT6, NAD and NAMPT levels in skeletal muscle of aged rats. Mech Ageing Dev. 2010; 131:21-28.

50. Marton O, Koltai E, Nyakas C, Bakonyi T, ZentenoSavin T, Kumagai S, Goto S, Radak Z. Aging and exercise affect the level of protein acetylation and SIRT1 activity in cerebellum of male rats. Biogerontology. 2010; 11:679-686.

51. Yang T, Sauve AA. NAD metabolism and sirtuins: metabolic regulation of protein deacetylation in stress and toxicity. AAPS J. 2006; 8:E632-643.

52. Chen Z, Yoo SH, Park YS, Kim KH, Wei S, Buhr E, Ye ZY, Pan HL, Takahashi JS. Identification of diverse modulators of central and peripheral circadian clocks by high-throughput chemical screening. Proc Natl Acad Sci U S A. 2012; 109:101-106. 